\title{
Erratum
}

Epidemiol. Infect. 128 (2002), 363-371

Z. ZHOU, J. OGASAWARA, Y. NISHIKAWA, et al.

\section{An outbreak of gastroenteritis in Osaka, Japan due to Escherichia coli serogroup 0166: H15 that had a coding gene for enteroaggregative $E$. coli heat-stable enterotoxin 1 (EAST1)}

Tables 1 and 2 were omitted, and follow:

Table 1. List of E. coli O166:H15 strains used in this study

\begin{tabular}{llll}
\hline \hline Strain & Origin & Date & Place \\
\hline $96-127-23$ & Outbreak & July 1996 & Osaka City, Japan \\
V-255 & Sporadic & December 1997 & Osaka City, Japan \\
V-471 & Sporadic & October 1998 & Osaka City, Japan \\
FK & Outbreak & September 1997 & Fukui Prefecture, Japan \\
\hline \hline
\end{tabular}

All strains were isolated from faecal specimens of patients.

Table 2. PCR used in this study

\begin{tabular}{|c|c|c|c|c|}
\hline Target & Primer $\left(5^{\prime}-3^{\prime}\right)$ & Condition & Product & Reference \\
\hline $\mathrm{LT}$ & $\begin{array}{l}\text { AGCAGGTTTCCCACCGGATCACCA } \\
\text { GTGCTCAGATTCTGGGTCTC }\end{array}$ & $\begin{array}{l}94{ }^{\circ} \mathrm{C} 30 \mathrm{sec}, 47^{\circ} \mathrm{C} 1 \mathrm{~min}, 72^{\circ} \mathrm{C} 1.5 \mathrm{~min} \\
25 \text { cycles }\end{array}$ & 132 bp & 10 \\
\hline ST & $\begin{array}{l}\text { TTTATTTCTGTATTGTCTTT } \\
\text { ATTACAACACAGTTCACAG }\end{array}$ & $\begin{array}{l}94{ }^{\circ} \mathrm{C} 30 \mathrm{sec}, 47^{\circ} \mathrm{C} 1 \mathrm{~min}, 72^{\circ} \mathrm{C} 1.5 \mathrm{~min} \\
25 \text { cycles }\end{array}$ & $171 \mathrm{bp}$ & 10 \\
\hline VT & $\begin{array}{l}\text { TTTACGATAGACTTCTCGAC } \\
\text { CACATATAAATTATTTCGCTC }\end{array}$ & $\begin{array}{l}94{ }^{\circ} \mathrm{C} 30 \mathrm{sec}, 47^{\circ} \mathrm{C} 1 \mathrm{~min}, 72^{\circ} \mathrm{C} 1.5 \mathrm{~min} \\
25 \text { cycles }\end{array}$ & $228 \mathrm{bp}$ & 10 \\
\hline $\operatorname{inv} \mathrm{E}$ & $\begin{array}{l}\text { ATATCTCTATTTCCAATCGCGT } \\
\text { GATGGCGAGAAATTATATCCCG }\end{array}$ & $\begin{array}{l}94{ }^{\circ} \mathrm{C} 30 \mathrm{sec}, 47^{\circ} \mathrm{C} 1 \mathrm{~min}, 72^{\circ} \mathrm{C} 1.5 \mathrm{~min} \\
25 \text { cycles }\end{array}$ & 382 bp & 10 \\
\hline eaeA & $\begin{array}{l}\text { ACGTTGCAGCATGGGTAACTC } \\
\text { GATCGGCAACAGTTTCACCTG }\end{array}$ & $\begin{array}{l}94^{\circ} \mathrm{C} 1 \mathrm{~min}, 55^{\circ} \mathrm{C} 1 \mathrm{~min}, 72^{\circ} \mathrm{C} 2 \mathrm{~min} \\
35 \text { cycles }\end{array}$ & 815 bp & 9 \\
\hline$b f p$ & $\begin{array}{l}\text { GATTGAATCTGCAATGGTGC } \\
\text { GGATTACTGTCCTCACATAT }\end{array}$ & $\begin{array}{l}94{ }^{\circ} \mathrm{C} 1 \mathrm{~min}, 57^{\circ} \mathrm{C} 1 \mathrm{~min}, 72{ }^{\circ} \mathrm{C} 80 \mathrm{sec} \\
30 \text { cycles }\end{array}$ & $597 \mathrm{bp}$ & 12 \\
\hline $\begin{array}{l}\text { Aggregative } \\
\text { adhesion }\end{array}$ & $\begin{array}{l}\text { CAATGTATAGAAATCCGCTGTT } \\
\text { CTGGCGAAAGACTGTATCAT }\end{array}$ & $\begin{array}{l}94{ }^{\circ} \mathrm{C} 1 \mathrm{~min}, 55^{\circ} \mathrm{C} 1 \mathrm{~min}, 72{ }^{\circ} \mathrm{C} 2 \mathrm{~min} \\
35 \text { cycles }\end{array}$ & $630 \mathrm{bp}$ & 11 \\
\hline EAST1 $(1 a, b)$ & $\begin{array}{l}\text { CCATCAACACAGTATATCCGA } \\
\text { GGTCGCGAGTGACGGCTTTGT }\end{array}$ & $\begin{array}{l}94^{\circ} \mathrm{C} 1 \mathrm{~min}, 55^{\circ} \mathrm{C} 1 \mathrm{~min}, 72^{\circ} \mathrm{C} 2 \mathrm{~min} \\
35 \text { cycles }\end{array}$ & $111 \mathrm{bp}$ & 6 \\
\hline EAST1 $(3 a, b)$ & $\begin{array}{l}\text { AGAACTGCTGGGTATGTGGCT } \\
\text { GTTGGATAAGCGAAGAACGTG }\end{array}$ & $\begin{array}{l}95^{\circ} \mathrm{C} 30 \mathrm{sec}, 55^{\circ} \mathrm{C} 2 \mathrm{~min}, 72^{\circ} \mathrm{C} 2 \mathrm{~min} \\
30 \text { cycles }\end{array}$ & $393 \mathrm{bp}$ & 6 \\
\hline
\end{tabular}

